\title{
Comparison of Empirical Models to Predict Viscosity of Secondary Vacuum Gas Oils
}

\author{
Dicho S. Stratiev ${ }^{1, *} \mathbb{D}^{\mathbb{D}}$, Svetoslav Nenov ${ }^{2}$, Ivelina K. Shishkova ${ }^{1}{ }^{\circledR}$, Rosen K. Dinkov ${ }^{1}$, Kamen Zlatanov ${ }^{2}$, \\ Dobromir Yordanov $^{3}$, Sotir Sotirov ${ }^{3}$, Evdokia Sotirova ${ }^{3}$, Vassia Atanassova ${ }^{4} \oplus$, Krassimir Atanassov ${ }^{3,4}$, \\ Danail D. Stratiev ${ }^{4}$ and Liliana Todorova-Yankova ${ }^{2}$
}

1 LUKOIL Neftohim Burgas, 8104 Burgas, Bulgaria; Shishkova.Ivelina.K@neftochim.bg (I.K.S.); Dinkov.Rosen.K@neftochim.bg (R.K.D.)

2 Department of Mathematics, University of Chemical Technology and Metallurgy, Kliment Ohridski 8, 1756 Sofia, Bulgaria; s.nenov@gmail.com (S.N.); kamenzlatanov99@gmail.com (K.Z.); litoian@abv.bg (L.T.-Y.)

3 Laboratory of Intelligent Systems, Department of Industrial Technologies and Management, University Prof. Dr. Assen Zlatarov, Professor Yakimov 1, 8010 Burgas, Bulgaria; dobromirj@abv.bg (D.Y.); ssotirov@btu.bg (S.S.); esotirova@btu.bg (E.S.); k.t.atanassov@gmail.com (K.A.)

4 Institute of Biophysics and Biomedical Engineering, Bulgarian Academy of Sciences, Bulgarian Academy of Sciences, Academic GeorgiBonchev 105, 1113 Sofia, Bulgaria; vassia.atanassova@gmail.com (V.A.); danail.stratiev@gmail.com (D.D.S.)

* Correspondence: stratiev.dicho@neftochim.bg

check for updates

Citation: Stratiev, D.S.; Nenov, S.; Shishkova, I.K.; Dinkov, R.K.; Zlatanov, K.; Yordanov, D.; Sotirov, S.; Sotirova, E.; Atanassova, V.; Atanassov, K.; et al. Comparison of Empirical Models to Predict Viscosity of Secondary Vacuum Gas Oils. Resources 2021, 10, 82. https:// doi.org/10.3390/resources10080082

Academic Editor: Ben Mclellan

Received: 8 July 2021

Accepted: 3 August 2021

Published: 10 August 2021

Publisher's Note: MDPI stays neutral with regard to jurisdictional claims in published maps and institutional affiliations.

Copyright: (c) 2021 by the authors. Licensee MDPI, Basel, Switzerland. This article is an open access article distributed under the terms and conditions of the Creative Commons Attribution (CC BY) license (https:// creativecommons.org/licenses/by/ $4.0 /)$.

\begin{abstract}
This work presents characterization data and viscosity of 34 secondary vacuum gas oils (HOil gas oils, visbreaker gas oils, and fluid catalytic cracking slurry oils) with aromatic content reaching up to $100 \mathrm{wt}$.\%. Inter-criteria analysis was employed to define the secondary VGO characteristic parameters which have an effect on viscosity. Seven published empirical models to predict viscosity of the secondary vacuum gas oils were examined for their prediction ability. The empirical model of Aboul-Seud and Moharam was found to have the lowest error of prediction. A modification of Aboul-Seoud and Moharam model by separating the power terms accounting for the effects of specific gravity and average boiling point improves the accuracy of viscosity prediction. It was discovered that the relation of slope of viscosity decrease with temperature enhancement for the secondary vacuum gas oil is not a constant. This slope increases with the average boiling point and the specific gravity augmentation, a fact that has not been discussed before.
\end{abstract}

Keywords: vacuum gas oil; FCC slurry oil; H-oil gas oil; visbreaker gas oil; viscosity; empirical modeling; intercriteria analysis

\section{Introduction}

Being an important input parameter in the chemical engineering design, viscosity prediction has concentrated the effort of many researchers on the development of various models that could estimate the viscosity of pure components and mixtures [1-3]. Whereas the prediction of pure liquid viscosity or two- or three-component mixture viscosity is a somewhat easier task, the prediction of viscosity of crude oils or petroleum fractions becomes much more complicated, because of the latter being undefined liquids. The complexity of the petroleum and its fractions has reflected in the development of different models predicting viscosity of distinct oils for the last 50 years [4-32]. Depending on how each prediction method has been developed, the methods could be categorized as theoretical, semi-theoretical or empirical. Theoretical models are based on statistical mechanics, and viscosity is related to the intermolecular potential functions [26]. Semitheoretical models have a theoretical basis but include parameters that must be determined through fitting of experimental viscosity data. The semi-theoretical models are based on the principle of corresponding states and cubic equations of state $[12,22,24]$. They can be considered applied statistical mechanics models, such as the reaction rate theory, 
hard sphere theory, square well theory or their modifications [12,24]. The methods of corresponding states are based on one or more reference fluids and rely on the principle that under the same reduced conditions, the same reduced viscosity is obtained for any of the fluids in a group [24]. These methods predict viscosities as functions of temperature, pressure, composition, pseudo-critical properties, and the viscosity of a reference fluid at a reference temperature and pressure. As such, they can only be related to two of the following properties: the reduced temperature, reduced pressure, reduced density, or reduced volume [22]. The equation of state (EOS) concept involves a mathematical relationship between volume, pressure, and temperature that includes compositional information when dealing with mixtures. It can be used for different states of matter but is mostly used for gases, and no EOS application has been found for petroleum fluids [22]. The semi-theoretical models are usually more accurate, but they are more complex and require parameters such as critical properties, chemical composition, acentric factor or other similar properties which in many cases are not available [20]. The empirical methods include a wide variety of equations used throughout the industry involving constants calculated from experimental data by regression. Machine learning (ML) and artificial intelligence techniques (AI) have also been used to improve the prediction of oil viscosity [27-32]. The literature argues that the lowest average absolute relative error can be achieved when viscosity is predicted by AI models and the highest correlation coefficient as compared to existing empirical correlations $[27,32]$. The empirical models are typically simpler and only require a few basic parameters such as mid-boiling point temperature and specific gravity of the oil, or alternatively a single viscosity measurement, in order to extrapolate the viscosity to a different temperature [20]. The input oil characterization data for the empirical methods predicting viscosity include density, average boiling point or $\mathrm{T}_{50 \%}$ or molecular weight $[4,5,10,11,13-18,20-22]$. Al-Maamari et al. [16] and Bahadori [18] introduced the correlating parameter, that is $(\mathrm{Sa} /(\mathrm{Ar}+\mathrm{Re}+\mathrm{As}))$ ratio (where $\mathrm{Sa}, \mathrm{Ar}, \mathrm{Re}$, and As are the contents of saturates, aromatics, resins, and asphaltenes, respectively); multiplied by the API to account for the effect of oil composition on viscosity. Sánchez-Minero et al. [17] account the effect of petroleum composition on its viscosity by the use of only API. As a whole, the higher the molecular weight (average boiling point or $\mathrm{T}_{50 \%}$ ) and the higher the density of the oil the higher the viscosity is. Our earlier research [19] evaluated the available in the literature empirical models to predict viscosity of petroleum fractions originating from 244 different crude oils. The correlation of Abbott [4] was found to be the most accurate in prediction viscosity of vacuum gas oils (VGOs). The correlation of Twu [5] was the second most accurate in prediction viscosity of vacuum gas oils [12]. The correlation of Fang [14] was next in the classification of the accuracy of prediction viscosity of vacuum gas oils. The empirical models mentioned above were examined against data for vacuum gas oils from primary origin. The secondary vacuum gas oils coming from the processes of heavy oil conversion like fluid catalytic cracking (FCC), coking, and hydrocracking are more aromatic and heavier than the primary vacuum gas oils [33-37]. Considering that the aromatic content affects viscosity [38] one may expect that the empirical models developed on the base of data for primary vacuum gas oils could exhibit a bigger deviation in their prediction when secondary vacuum gas oils are examined. Unfortunately, information about viscosity of secondary vacuum gas oils in the literature is scarce. That is why it is very difficult, or even impossible, to verify the capability of the existing oil viscosity models to predict viscosity of the high aromatic secondary vacuum gas oils. That was the reason for us to characterize 23 secondary vacuum gas oils and a blended VGO consisting of about $70 \%$ hydrotreated straight run VGO and about 30\% VGO coming from H-Oil vacuum residue hydrocracking and measure their viscosity. The content of aromatic compounds in these 24 VGOs, measured in accordance with ASTM D2549 standard, varied between $47.8 \%$ and $100 \%$. The empirical models of Abbott [4], Twu [5], and Fang [14], which exhibited a satisfactory prediction of primary VGO viscosity were verified for their prediction ability for these 24 secondary VGOs. The models of Aboul-Seoud and Moharam [15], SánchezMinero et al. [17], AlMulla and Albahri [20], and Kotzakoulakis and George [21] were also 
examined for their capability to correctly predict the viscosity of the 24 secondary VGOs. Analyzing the results of the comparison between measured and predicted viscosity by the seven tested models, a modification of the best model was proposed and a verification with another set of 10 secondary VGOs for the new model and the best published model was performed. The aim of this work is to discuss the obtained results.

\section{Materials and Methods}

Properties of the secondary VGOs under study are presented in Table 1. The methods employed to measure their properties are given below:

- Density, g/ $\mathrm{cm}^{3}$ ASTM D4052;

- $\quad$ High temperature simulation distillation (HTSD) Ŵ ASTM D7169;

- Engler specific viscosity ASTM D1665;

- Hydrocarbon composition ASTM D2549.

Conversion of Engler specific viscosity in kinematic viscosity was done as follows [39]:

$$
\text { Kin. vis. }=7.41 \text { Engler specific viscosity }
$$

where Kin. vis. = kinematic viscosity, $\mathrm{mm}^{2} / \mathrm{s}$. Engler specific viscosity $=$ Engler specific viscosity, ${ }^{\circ} \mathrm{E}$

The correlations used to estimate some of the properties of the studied secondary VGOs are summarized below.

Molecular weight was estimated by the correlation developed by Linan et al. for heavy oils[40] and shown as Equation (2).

$M_{w}=284.75[\exp (0.00322(A B P+273.15))][\exp (-2.52 S G)] \times(A B P+273.15)^{0.083} S G^{2.44}$

The refractive index was estimated by the correlation of Stratiev et al. [41] and shown as Equation (3).

$$
R I_{L N B}=0.702091 d_{15}-0.00011 T_{50}+0.91493
$$

The characterization factor $(K w)$ was estimated by Equation (4).

$$
K w=\frac{\sqrt[3]{1.8\left[\frac{T 10+T 50+T 90}{3}+273.15\right]}}{d_{15}}
$$

The aromatic ring index (ARI), developed by Abutaqiya et al. [42,43] is estimated by Equations (5) and (6).

$$
A R I=f\left(M W, F_{R I}\right)=\frac{2\left[\frac{M W}{F_{R I}}-(3.5149 M W+73.1858]\right.}{(3.5074 M W-91.972-(3.5149 M W+73.1858)}
$$

where,

$M W=$ molecular weight of EBVRHC heavy oils, $\mathrm{g} / \mathrm{mol}$;

$F R I=$ function of refractive index.

$$
F_{R I}=\frac{n_{D 20}^{2}-1}{n_{D 20}^{2}+2}
$$

where, $n_{D 20}=$ refractive index at $20^{\circ} \mathrm{C}$.

The empirical models published in the open literature and employed to predict viscosity of the studied 24 secondary vacuum gas oils are summarized in Table 2. 
Table 1. Properties of the secondary vacuum gas oils under study.

\begin{tabular}{|c|c|c|c|c|c|c|c|c|c|c|c|c|c|c|c|c|c|}
\hline $\mathrm{Nr}$ & Sample & $\begin{array}{c}\text { Density } \\
\text { at } 15^{\circ} \mathrm{C} \text {, } \\
\mathrm{g} / \mathrm{cm}^{3}\end{array}$ & SG & API & $\mathrm{T}_{10 \%}$ & $\mathrm{~T}_{50 \%}$ & $\mathrm{~T}_{90 \%}$ & $T_{95 \%}$ & $\begin{array}{c}\mathrm{ABP}, \\
{ }^{\circ} \mathrm{C}\end{array}$ & $\begin{array}{c}\text { Kin. vis. } \\
\text { at } 80{ }^{\circ} \mathrm{C}, \\
\mathrm{mm}^{2} / \mathrm{s}\end{array}$ & $\begin{array}{c}\text { Kin. vis at } \\
98.9^{\circ} \mathrm{C} \\
\mathrm{mm}^{2} / \mathrm{s}\end{array}$ & $\begin{array}{l}\text { RI at } \\
20^{\circ} \mathrm{C}\end{array}$ & Kw & $\begin{array}{l}\text { MW, } \\
\text { g/mol }\end{array}$ & ARI & Sat. & Aromatics \\
\hline 1 & HAGO-1 & 0.9504 & 0.9512 & 17.3 & 343 & 397 & 455 & 476 & 398 & 7.3 & 4.6 & 1.5385 & 11.21 & 342 & 2.2 & 38.4 & 61.6 \\
\hline 3 & HVGO-1 & 0.9849 & 0.9858 & 12.0 & 426 & 491 & 548 & 562 & 488 & 49.9 & 22.9 & 1.5524 & 11.28 & 462 & 3.0 & 24.4 & 75.6 \\
\hline 4 & HAGO-2 & 0.9582 & 0.9590 & 16.0 & 335 & 395 & 458 & 480 & 396 & 13.6 & 7.9 & 1.5442 & 11.10 & 339 & 2.3 & 35.6 & 64.4 \\
\hline 5 & LVGO-2 & 0.9847 & 0.9856 & 12.1 & 330 & 410 & 488 & 508 & 409 & 15.2 & 8.6 & 1.5612 & 10.88 & 355 & 2.7 & 26.3 & 73.7 \\
\hline 6 & HVGO-2 & 1.0075 & 1.0084 & 8.8 & 430 & 489 & 540 & 554 & 486 & 62.1 & 27.4 & 1.5685 & 11.02 & 458 & 3.4 & 17.0 & 83.0 \\
\hline 8 & LVGO-3 & 0.9760 & 0.9768 & 13.4 & 324 & 395 & 482 & 508 & 400 & 16.7 & 9.3 & 1.5567 & 10.92 & 344 & 2.5 & 29.2 & 70.8 \\
\hline 9 & HVGO-3 & 0.9961 & 0.9970 & 10.4 & 405 & 470 & 534 & 551 & 470 & 34.8 & 17.1 & 1.5626 & 11.06 & 434 & 3.1 & 21.1 & 78.9 \\
\hline 10 & FCC SLO-1 & 0.9862 & 0.9871 & 11.9 & 232 & 282 & 412 & 455 & 309 & 3.6 & 2.5 & 1.5763 & 10.30 & 253 & 2.4 & 27.7 & 72.3 \\
\hline 11 & FCC SLO-2 & 1.054 & 1.0549 & 2.6 & 292 & 372 & 475 & 518 & 380 & 9.9 & 6.0 & 1.6140 & 10.01 & 319 & 3.3 & 8.6 & 91.4 \\
\hline 12 & FCC SLO-3 & 1.0564 & 1.0573 & 2.3 & 329 & 392 & 471 & 493 & 397 & 16.2 & 9.1 & 1.6135 & 10.08 & 338 & 3.5 & 7.4 & 92.6 \\
\hline 13 & FCC SLO-4 & 1.0662 & 1.0671 & 1.1 & 337 & 401 & 476 & 498 & 405 & 21.3 & 11.4 & 1.6194 & 10.02 & 345 & 3.6 & 5.1 & 94.9 \\
\hline 14 & FCC SLO-5 & 1.0615 & 1.0624 & 1.7 & 324 & 391 & 471 & 494 & 395 & 17.4 & 9.7 & 1.6172 & 10.02 & 335 & 3.5 & 6.4 & 93.6 \\
\hline 15 & FCC SLO-6 & 1.0943 & 1.0953 & -2.3 & 331 & 400 & 491 & 525 & 407 & 33.8 & 16.7 & 1.6392 & 9.78 & 346 & 3.9 & 0.0 & 100.0 \\
\hline 16 & FCC SLO-7 & 1.0779 & 1.0788 & -0.3 & 326 & 397 & 493 & 531 & 405 & 24.2 & 12.7 & 1.6280 & 9.92 & 345 & 3.7 & 2.7 & 97.3 \\
\hline 18 & FCC SLO-9 & 1.0826 & 1.0835 & -0.9 & 327 & 401 & 480 & 501 & 403 & 28.5 & 14.5 & 1.6309 & 9.86 & 342 & 3.8 & 2.0 & 98.0 \\
\hline 19 & FCC SLO-10 & 1.1760 & 1.1770 & -11.3 & 371 & 435 & 562 & 634 & 456 & 312.8 & 97.1 & 1.6927 & 9.31 & 395 & 5.1 & 0.0 & 100.0 \\
\hline 20 & FCC SLO-11 & 1.1001 & 1.1011 & -3.0 & 332 & 394 & 482 & 530 & 403 & 21.2 & 11.4 & 1.6440 & 9.70 & 340 & 3.9 & 0.0 & 100.0 \\
\hline 21 & VGO blend & 0.9157 & 0.9165 & 22.9 & 376 & 446 & 525 & 544 & 449 & 14.2 & 8.1 & 1.5088 & 11.92 & 404 & 1.7 & 52.2 & 47.8 \\
\hline 22 & HAGO-4 & 0.9041 & 0.905 & 24.9 & 357 & 425 & 489 & 505 & 424 & 8.0 & 4.9 & 1.5029 & 11.93 & 370 & 1.4 & 46.4 & 53.6 \\
\hline 23 & LVGO-4 & 0.9112 & 0.912 & 23.7 & 322 & 417 & 528 & 550 & 422 & 8.6 & 5.2 & 1.5088 & 11.83 & 369 & 1.6 & 51.0 & 49.0 \\
\hline 24 & HVGO-4 & 0.9211 & 0.922 & 22.0 & 411 & 486 & 552 & 568 & 483 & 27.2 & 13.5 & 1.5082 & 12.03 & 453 & 1.8 & 45.6 & 54.4 \\
\hline
\end{tabular}


Table 2. Empirical models to predict VGO viscosity.

\begin{tabular}{|c|c|c|c|c|}
\hline Correlation Used & Equation & API & ABP, K & SG \\
\hline \multirow[t]{2}{*}{ Abbott [4] } & $\begin{aligned} \log _{10} \operatorname{VIS}(98.89)= & -0.463634-0.166532 A P I \\
& +5.13447 \times 10^{-4} A P I^{2} \\
& -8.48995 \times 10^{-3} K_{W} A P I+F\end{aligned}$ & $10.1^{\circ}-50.3^{\circ}$ & $427.15-889.15$ & - \\
\hline & $F=\frac{8.0325 \times 10^{-2} K_{W}+1.24899 A P I+0.19768 A P I^{2}}{A P I+26.786-2.6296 K_{W}}$ & & & \\
\hline Twu [5] & $\begin{aligned} T_{C}^{\circ}=A B P(0.533272 & +0.191017 \times 10^{-3} A B P \\
+ & 0.779681 \times 10^{-7} A B P^{2} \\
& -0.284376 \times 10^{-10} A B P^{3} \\
& \left.+0.959468 \times \frac{10^{28}}{A B P^{13}}\right)^{-1}\end{aligned}$ & - & - & - \\
\hline Fang [14] & $\begin{array}{l}\ln \frac{V I S}{T}=59.06 A B P^{0.1546} M_{W}^{0.4791} \frac{\rho}{T}-\left(18.103+\ln M_{W}\right) \\
\rho=\left(\rho_{15.6}^{2}-0.0011(t-15.6)^{0.5}\right.\end{array}$ & - & $363.15-727.15$ & $0.73-0.90$ \\
\hline $\begin{array}{l}\text { Aboul-Seoud and } \\
\text { Moharam [15] }\end{array}$ & $\begin{array}{l}\ln \ln (V I S+0.8)=a_{1}+a_{2} \ln (T) \\
a_{1}=4.3414 \times(A B P \times S G)^{0.2}+6.6913 \\
a_{2}=-3.7\end{array}$ & - & $323.15-773.15$ & - \\
\hline AlMulla and Albahri [20] & $V^{\prime} S_{98.89}=8.7903\left[\frac{-31864.442+37377.083 S G-14.374 A B P}{-30178.282+35974.1 S G-15.239 A B P}\right]^{-33.0834}$ & - & $450.65-883.45$ & $0.769-0.952$ \\
\hline Sánchez-Minero [17] & $\begin{array}{l}\mu_{o d}=\operatorname{aexp}\left(b / T^{3}\right) \\
a=3.9 \times 10^{-5} A P I^{3}-4.0 \times 10^{-3} A P I^{2}+0.1226 A P I-0.7626 \\
b=9.1638 \times 10^{9} A P I^{-1.3257}\end{array}$ & $12.4^{\circ}-43^{\circ}$ & 303.15-333.15 & - \\
\hline Kotzakoulakis [21] & $\ln \ln (V I S+0.8)=14.69 A B P^{0.0684} S G^{0.267}-3.682 \ln (T)$ & - & $358-873$ & $0.806-1.024$ \\
\hline
\end{tabular}

\section{Results}

\subsection{Relations of the Secondary VGO Properties to Viscosity}

In order to evaluate the relations of the characteristics of the studied VGOs from Table 1 and to define these having the strongest impact on VGO viscosity, inter-criteria analysis (ICrA) was performed. The ICrA approach is specifically designed for datasets comprising evaluations, or measurements of multiple objects against multiple criteria. The building blocks of the presented ICrA for decision support are the two concepts of intuitionistic fuzziness and index matrices. Intuitionistic fuzzy sets defined by Atanassov [44-47] are one of the most popular and well investigated extensions of the concept of fuzzy sets, defined by Zadeh. Besides the traditional function of membership $\mu \mathrm{A}(\mathrm{x})$ defined in fuzzy sets to evaluate the membership of an element $x$ to the set $A$ with a real number in the [0; 1]-interval, in intuitionistic fuzzy sets (IFSs) a second function has been introduced, $v \mathrm{~A}(\mathrm{x})$ defining, respectively, the non-membership of the element $\mathrm{x}$ to the set $\mathrm{A}$, which may coexist with the membership function. More formally the IFS itself is formally denoted by

$$
\mathrm{A}=\{\langle\mathrm{x}, \mu \mathrm{A}(\mathrm{x}), v \mathrm{~A}(\mathrm{x})\rangle \mid \mathrm{x} \in \mathrm{E}\}
$$

and the following conditions hold:

$$
\begin{gathered}
0 \leq \mu \mathrm{A}(\mathrm{x}) \leq 1,0 \leq \nu \mathrm{A}(\mathrm{x}) \leq 1 \\
0 \leq \mu \mathrm{A}(\mathrm{x})+\nu \mathrm{A}(\mathrm{x}) \leq 1 .
\end{gathered}
$$

Multiple relations, operations, modal and topological operators have been defined over IFS, showing that IFSs are a non-trivial extension of the concept of fuzzy sets. 
The second concept, on which the proposed method is based, is the concept of index matrix, a matrix which features two index sets. The basics of the theory behind the index matrices are described in [48], and recently developed further in [49].

In the ICrA approach, the raw data for processing are put within an index matrix $M$ of $m$ rows $\left\{O_{1}, \ldots, O_{m}\right\}$ and $n$ columns $\left\{C_{1}, \ldots, C_{n}\right\}$, where for every $p, q(1 \leq p \leq m, 1 \leq q$ $\leq n), O_{p}$ in an evaluated object, $C_{q}$ is an evaluation criterion, and $e_{O p C q}$ is the evaluation of the $p$-th object against the $q$-th criterion, defined as a real number or another object that is comparable according to relation $R$ with all of the remaining elements of the index matrix $M$.

$$
\begin{array}{c|ccccccc} 
& C_{1} & \ldots & C_{k} & \ldots & C_{l} & \ldots & C_{n} \\
\hline O_{1} & e_{O_{1}, C_{1}} & \ldots & e_{O_{1}, C_{k}} & \ldots & e_{O_{1}, C_{l}} & \ldots & e_{O_{1}, C_{n}} \\
\vdots & \vdots & \ddots & \vdots & \ddots & \vdots & \ddots & \vdots \\
O_{i} & e_{O_{i}, C_{1}} & \ldots & e_{O_{i}, C_{k}} & \ldots & e_{O_{i}, C_{l}} & \ldots & e_{O_{i}, C_{n}} \\
\vdots & \vdots & \ddots & \vdots & \ddots & \vdots & \ddots & \vdots \\
O_{j} & e_{O_{j}, C_{1}} & \ldots & e_{O_{j}, C_{k}} & \ldots & e_{O_{j}, C_{l}} & \ldots & e_{O_{j}, C_{n}} \\
\vdots & \vdots & \ddots & \vdots & \ddots & \vdots & \ddots & \vdots \\
O_{m} & e_{O_{m}, C_{1}} & \ldots & e_{O_{m}, C_{j}} & \ldots & e_{O_{m}, C_{l}} & \ldots & e_{O_{m}, C_{n}}
\end{array}
$$

From the requirement for comparability above, it follows that for each $i, j, k$ it holds the relation $R\left(e_{\mathrm{OiCk}}, e_{\mathrm{OjCk}}\right)$. The relation $R$ has dual relation, which is true in the cases when relation $R$ is false, and vice versa.

For the needs of our decision making method, pairwise comparisons between every two different criteria are made along all evaluated objects. During the comparison, it is maintained one counter of the number of times when the relation $R$ holds, and another counter for the dual relation.

Let $S_{k, l}^{\mu}$ be the number of cases in which the relations $R\left(e_{\mathrm{OiCk}}, e_{\mathrm{OjCk}}\right)$ and $R\left(e_{\mathrm{OiCl}}, e_{\mathrm{OjCl}}\right)$ are simultaneously satisfied. Let also $S_{k, l}^{\nu}$ be the number of cases in which the relations $R$ $\left(e_{\mathrm{OiCk}}, e_{\mathrm{OjCl}}\right)$ and its dual $\bar{R}\left(e_{\mathrm{OiCl}}, e_{\mathrm{OjCl}}\right)$ are simultaneously satisfied. As the total number of pairwise comparisons between the object is $m(m-1) / 2$, it is seen that there hold the inequalities:

$$
0 \leq S_{k, l}^{\mu}+S_{k, l}^{v} \leq \frac{m(m-1)}{2}
$$

For every $k, l$, such that $1 \leq k \leq l \leq m$, and for $m \geq 2$ two numbers are defined:

$$
\mu_{C_{k}, C_{l}}=2 \frac{S_{k, l}^{\mu}}{m(m-1)}, v_{C_{k}, C_{l}}=2 \frac{S_{k, l}^{v}}{m(m-1)}
$$

The pair, constructed from these two numbers, plays the role of the intuitionistic fuzzy evaluation of the relations that can be established between any two criteria $C_{k}$ and $C_{l}$. In this way, the index matrix $M$ that relates evaluated objects with evaluating criteria can be transformed to another index matrix $M^{*}$ that gives the relations among the criteria:

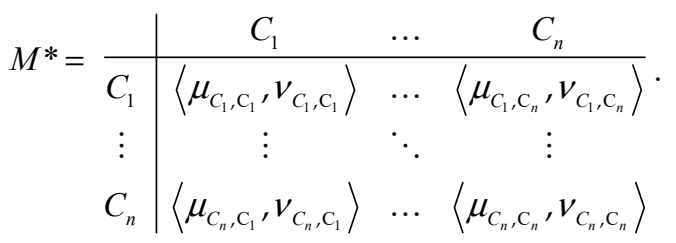

From practical considerations, it was more flexible to work with two index matrices $M^{\mu}$ and $M^{v}$, rather than with the index matrix $M^{*}$ of IF pairs. 
The final step of the algorithm is to determine the degrees of correlation between the criteria, depending on the user's choice of $\mu$ and $\nu$. We call these correlations between the criteria: 'positive consonance', 'negative consonance' or 'dissonance'. Let $\alpha, \beta \in[0 ; 1]$ be the threshold values, against which we compare the values of $\mu_{C k C l}$ and $v_{C k}, \mathrm{Cl}$. We call these criteria $C_{k}$ and $C_{l}$ in:

- $\quad(\alpha, \beta)$-positive consonance, if $\mu_{C k, C l}>\alpha$ and $v_{C k, C l}<\beta$;

- $\quad(\alpha, \beta)$-negative consonance, if $\mu_{C k, C l}<\beta$ and $v_{C k, C l}>\alpha$;

- $\quad(\alpha, \beta)$-dissonance, otherwise.

The approach is completely data driven, and each new application would require taking specific threshold values $\alpha, \beta$ that will yield reliable results. Various applications and suggested approaches to defining the thresholds have been discussed in a series of publications, available in [50].

Tables 3 and 4 present the statistically meaningful relations quantified by $\mu$ and $v$ value of ICrA for the evaluated vacuum gas oils. It is evident from these data that the parameter that has the biggest impact on viscosity is $\mathrm{T}_{95 \%}$. Figure $1 \mathrm{a}$ illustrates the relation of VGO viscosity to $\mathrm{T}_{95 \%}$. It is in line with the empirical model proposed by Mehrota $[10,12]$ highlighting the influence of the petroleum fraction boiling point on its viscosity. The data in Figure 1a also show that two different curves can be distinguished. The first is related to the secondary VGOs which have an aromatic ring index higher than 2 . The second curve concerns the VGOs which have an ARI lower than 2. The data in Figure 1b suggest that the ARI also has a considerable impact on the VGO viscosity. These findings support the conclusion made by Redelius and Soenen [38] that both molecular weight (the molecular weight correlates with VGO boiling point) and aromaticity (expressed by ARI or density) are the main factors controlling the studied VGO viscosity. As was reported in our recent study [51] the most informative properties of a VGO are the average boiling point, or $\mathrm{T}_{50 \%}$, and density, or specific gravity (SG). That is why the empirical models employed to evaluate their viscosity prediction ability in this work are based on these two VGO properties.

Table 3. $\mu$-value of the ICrA evaluation of relations between properties of the studied secondary vacuum gas oils.

\begin{tabular}{|c|c|c|c|c|c|c|c|c|c|c|c|c|c|c|}
\hline & $\mathrm{D}_{15}$ & $\mathrm{~T}_{10 \%}$ & $\mathbf{T}_{50 \%}$ & $\mathrm{~T}_{90 \%}$ & $\mathbf{T}_{95 \%}$ & $\begin{array}{c}\mathrm{ABP}, \\
{ }^{\circ} \mathrm{C}\end{array}$ & $\begin{array}{l}\text { VIS } \\
80\end{array}$ & $\begin{array}{l}\text { VIS } \\
98.9\end{array}$ & $\begin{array}{l}\text { RI at } \\
20^{\circ} \mathrm{C}\end{array}$ & Kw & MW & ARI & Sat. & Aro \\
\hline $\mathrm{D}_{15}$ & 1.00 & 0.46 & 0.42 & 0.51 & 0.56 & 0.46 & 0.74 & 0.74 & 0.97 & 0.07 & 0.44 & 0.96 & 0.02 & 0.97 \\
\hline $\mathrm{T}_{10 \%}$ & 0.46 & 1.00 & 0.86 & 0.71 & 0.67 & 0.83 & 0.67 & 0.66 & 0.43 & 0.60 & 0.84 & 0.48 & 0.52 & 0.46 \\
\hline $\mathrm{T}_{50 \%}$ & 0.42 & 0.86 & 1.00 & 0.82 & 0.76 & 0.93 & 0.66 & 0.66 & 0.39 & 0.63 & 0.96 & 0.45 & 0.55 & 0.42 \\
\hline $\mathrm{T}_{90 \%}$ & 0.51 & 0.71 & 0.82 & 1.00 & 0.92 & 0.86 & 0.72 & 0.72 & 0.49 & 0.53 & 0.85 & 0.53 & 0.47 & 0.51 \\
\hline $\mathrm{T}_{95 \%}$ & 0.56 & 0.67 & 0.76 & 0.92 & 1.00 & 0.81 & 0.75 & 0.75 & 0.54 & 0.47 & 0.79 & 0.57 & 0.43 & 0.56 \\
\hline $\mathrm{ABP}{ }^{\circ} \mathrm{C}$ & 0.46 & 0.83 & 0.93 & 0.86 & 0.81 & 1.00 & 0.70 & 0.69 & 0.43 & 0.59 & 0.96 & 0.49 & 0.51 & 0.46 \\
\hline VIS 80 & 0.74 & 0.67 & 0.66 & 0.72 & 0.75 & 0.70 & 1.00 & 1.00 & 0.71 & 0.33 & 0.68 & 0.74 & 0.26 & 0.72 \\
\hline VIS 98.9 & 0.74 & 0.66 & 0.66 & 0.72 & 0.75 & 0.69 & 1.00 & 1.00 & 0.71 & 0.33 & 0.67 & 0.74 & 0.26 & 0.72 \\
\hline $\mathrm{RI}$ at $20^{\circ} \mathrm{C}$ & 0.97 & 0.43 & 0.39 & 0.49 & 0.54 & 0.43 & 0.71 & 0.71 & 1.00 & 0.04 & 0.41 & 0.93 & 0.04 & 0.94 \\
\hline $\mathrm{Kw}$ & 0.07 & 0.60 & 0.63 & 0.53 & 0.47 & 0.59 & 0.33 & 0.33 & 0.04 & 1.00 & 0.63 & 0.10 & 0.89 & 0.09 \\
\hline MW & 0.44 & 0.84 & 0.96 & 0.85 & 0.79 & 0.96 & 0.68 & 0.67 & 0.41 & 0.63 & 1.00 & 0.46 & 0.54 & 0.44 \\
\hline ARI & 0.96 & 0.48 & 0.45 & 0.53 & 0.57 & 0.49 & 0.74 & 0.74 & 0.93 & 0.10 & 0.46 & 1.00 & 0.03 & 0.96 \\
\hline Sat. & 0.02 & 0.52 & 0.55 & 0.47 & 0.43 & 0.51 & 0.26 & 0.26 & 0.04 & 0.89 & 0.54 & 0.03 & 1.00 & 0.01 \\
\hline Aro & 0.97 & 0.46 & 0.42 & 0.51 & 0.56 & 0.46 & 0.72 & 0.72 & 0.94 & 0.09 & 0.44 & 0.96 & 0.01 & 1.00 \\
\hline
\end{tabular}

Note: Green color means statistically meaningful positive relation; Red color implies statistically meaningful negative relation. The intensity of the color designates the strength of the relation. The higher the color intensity, the higher the strength of the relation is. Yellow color denotes dissonance. 
Table 4. $v$-value of the ICrA evaluation of relations between properties of the studied secondary vacuum gas oils.

\begin{tabular}{|c|c|c|c|c|c|c|c|c|c|c|c|c|c|c|}
\hline & $\mathrm{D}_{15}$ & $\mathrm{~T}_{10 \%}$ & $\mathrm{~T}_{50 \%}$ & $\mathrm{~T}_{90 \%}$ & $\mathrm{~T}_{95 \%}$ & $\begin{array}{c}\mathrm{ABP}, \\
{ }^{\circ} \mathrm{C}\end{array}$ & $\begin{array}{c}\text { VIS } \\
80\end{array}$ & $\begin{array}{l}\text { VIS } \\
98.9\end{array}$ & $\begin{array}{l}\text { RI at } \\
20^{\circ} \mathrm{C}\end{array}$ & Kw & MW & ARI & Sat. & Aro \\
\hline $\mathrm{D}_{15}$ & 0.00 & 0.53 & 0.57 & 0.48 & 0.43 & 0.52 & 0.26 & 0.26 & 0.03 & 0.91 & 0.55 & 0.02 & 0.97 & 0.02 \\
\hline $\mathrm{T}_{10 \%}$ & 0.53 & 0.00 & 0.12 & 0.27 & 0.32 & 0.15 & 0.33 & 0.33 & 0.55 & 0.38 & 0.14 & 0.49 & 0.46 & 0.52 \\
\hline $\mathrm{T}_{50 \%}$ & 0.57 & 0.12 & 0.00 & 0.16 & 0.22 & 0.04 & 0.33 & 0.33 & 0.59 & 0.34 & 0.03 & 0.53 & 0.42 & 0.55 \\
\hline $\mathrm{T}_{90 \%}$ & 0.48 & 0.27 & 0.16 & 0.00 & 0.06 & 0.11 & 0.27 & 0.27 & 0.50 & 0.45 & 0.13 & 0.45 & 0.51 & 0.47 \\
\hline $\mathrm{T}_{95 \%}$ & 0.43 & 0.32 & 0.22 & 0.06 & 0.00 & 0.17 & 0.25 & 0.25 & 0.45 & 0.51 & 0.20 & 0.41 & 0.56 & 0.43 \\
\hline $\mathrm{ABP}{ }^{\circ} \mathrm{C}$ & 0.52 & 0.15 & 0.04 & 0.11 & 0.17 & 0.00 & 0.29 & 0.29 & 0.55 & 0.38 & 0.02 & 0.49 & 0.46 & 0.51 \\
\hline VIS 80 & 0.26 & 0.33 & 0.33 & 0.27 & 0.25 & 0.29 & 0.00 & 0.00 & 0.29 & 0.65 & 0.32 & 0.24 & 0.72 & 0.26 \\
\hline VIS 98.9 & 0.26 & 0.33 & 0.33 & 0.27 & 0.25 & 0.29 & 0.00 & 0.00 & 0.28 & 0.65 & 0.32 & 0.24 & 0.72 & 0.26 \\
\hline $\mathrm{RI}$ at $20^{\circ} \mathrm{C}$ & 0.03 & 0.55 & 0.59 & 0.50 & 0.45 & 0.55 & 0.29 & 0.28 & 0.00 & 0.94 & 0.58 & 0.05 & 0.94 & 0.04 \\
\hline $\mathrm{Kw}$ & 0.91 & 0.38 & 0.34 & 0.45 & 0.51 & 0.38 & 0.65 & 0.65 & 0.94 & 0.00 & 0.35 & 0.88 & 0.09 & 0.89 \\
\hline MW & 0.55 & 0.14 & 0.03 & 0.13 & 0.20 & 0.02 & 0.32 & 0.32 & 0.58 & 0.35 & 0.00 & 0.52 & 0.44 & 0.54 \\
\hline ARI & 0.02 & 0.49 & 0.53 & 0.45 & 0.41 & 0.49 & 0.24 & 0.24 & 0.05 & 0.88 & 0.52 & 0.00 & 0.95 & 0.02 \\
\hline Sat. & 0.97 & 0.46 & 0.42 & 0.51 & 0.56 & 0.46 & 0.72 & 0.72 & 0.94 & 0.09 & 0.44 & 0.95 & 0.00 & 0.99 \\
\hline Aro & 0.02 & 0.52 & 0.55 & 0.47 & 0.43 & 0.51 & 0.26 & 0.26 & 0.04 & 0.89 & 0.54 & 0.02 & 0.99 & 0.00 \\
\hline
\end{tabular}

Note: Green color means statistically meaningful positive relation; Red color implies statistically meaningful negative relation. The intensity of the color designates the strength of the relation. The higher the color intensity, the higher the strength of the relation is. Yellow color denotes dissonance.

\subsection{Evaluation of the Secondary VGO Viscosity Prediction Ability of Studied Empirical Models}

To evaluate the accuracy of the employed empirical models to predict the secondary VGO viscosity the following statistical parameters were used [52]:

$$
\begin{gathered}
\text { Error }(E): E=\left(\frac{v_{\text {exp }}-v_{\text {calc }}}{v_{\text {exp }}}\right) \times 100 \\
\text { Standard error }(S E): S E_{i}=\left(\sum\left(\frac{\left(v_{\text {exp }}-v_{\text {calc }}\right)^{2}}{N-2}\right)\right)^{\frac{1}{2}}
\end{gathered}
$$

Relative standard error $(R S E): R S E_{i}=\frac{\mathrm{SE}}{\text { mean of the sample }} * 100$

$$
\text { Sum of square errors }(S S E): S S E=\sum \frac{1}{v_{\exp }^{2}}\left(v_{\text {exp }}-v_{\text {calc }}\right)^{2}
$$

$$
\text { Residual }(R): R=v_{\text {exp }}-v_{\text {calc }}
$$

Average absolute deviation $(\% A A D): \% A A D=\frac{1}{N} \frac{\sum\left|v_{\exp }-v_{\text {calc }}\right|}{v_{\exp }} * 100$

Table 5 summarizes the statistical analyses for the seven empirical models. In addition, the minimum error $(\min E)$, maximum error $(\max E)$, number of positive residuals $(\# R+)$, negative residuals $(\# R-)$, range calculated by the difference between the highest positive residual (HPR) and the lowest negative residual (LNR), are presented to provide a sound evaluation of each empirical model. It is evident from the data in Table 5 that the empirical model of Aboul-Seoud and Moharam [15] exhibited the lowest minimum and maximum error. It also showed the lowest standard error (SE), relative standard error (RSE), sum of squared error (SSE) and \%AAD. The number of over- and underestimations, assessed by $(\# R+)$, and (\#R-), and HPR and LNR, pointed out that the empirical model of Aboul-Seoud and Moharam [15] is the most balanced. In other words, the best prediction ability of the viscosity of the secondary VGOs from Table 1 exhibited the empirical model of AboulSeoud and Moharam [15]. One can see from the data in Table 5 that the empirical models of Sanchez-Minero et al. [17], and Fang and Lei [14] were found not applicable for the secondary VGO viscosity prediction. 


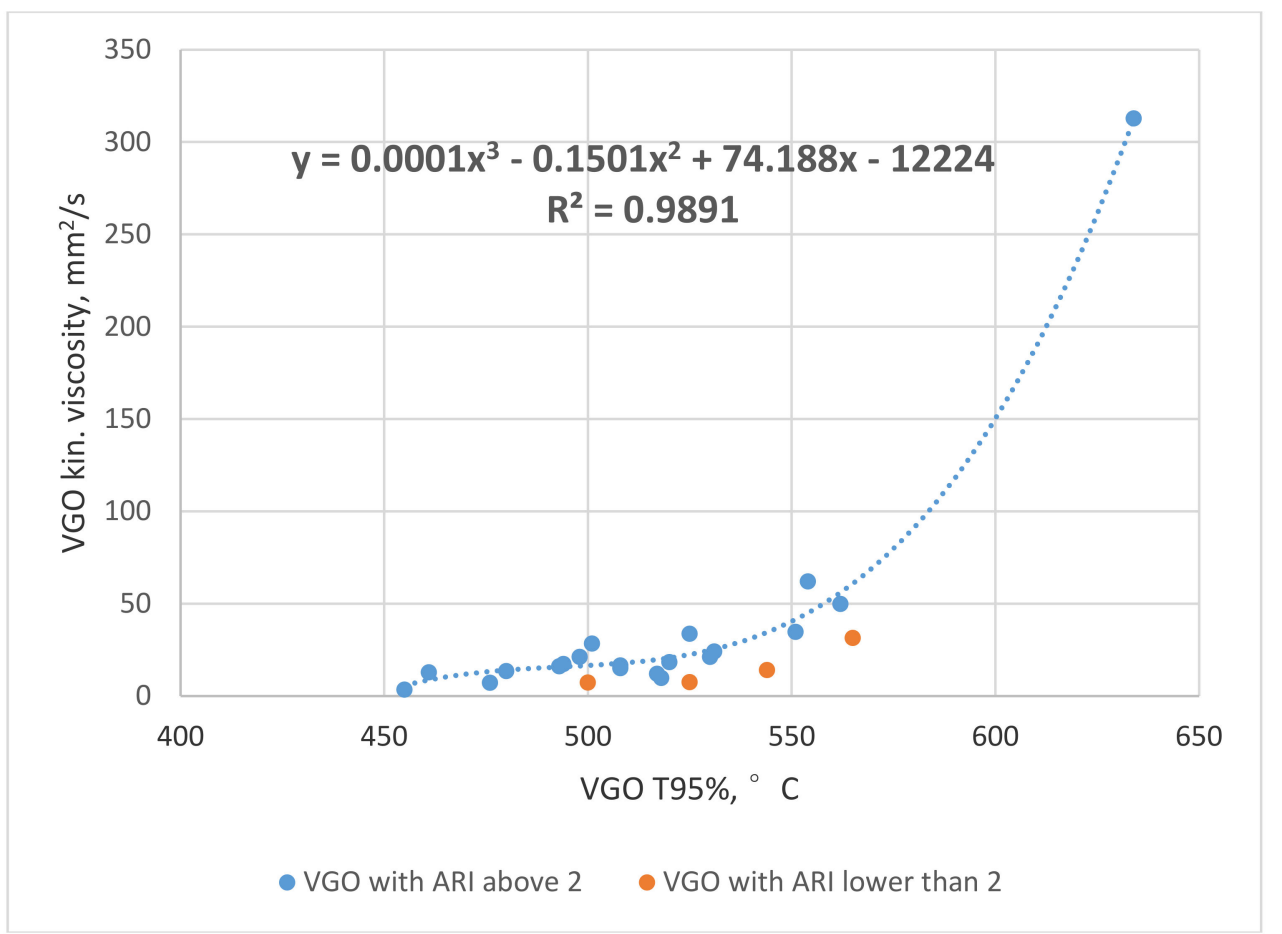

(a)

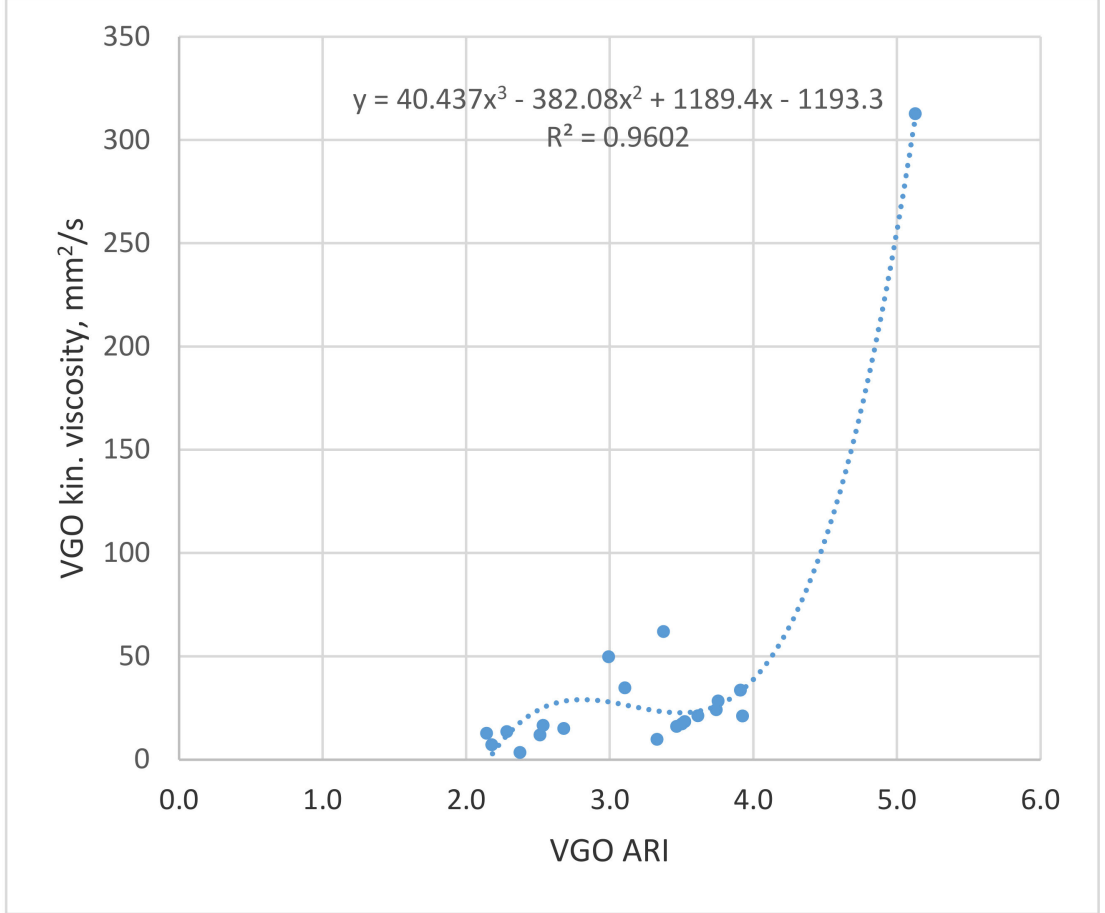

(b)

Figure 1. Dependence of VGO viscosity on VGO $\mathrm{T}_{95 \%}$ (a) and on aromatic ring index (ARI) (b). 
Table 5. Statistical analysis of the seven tested empirical models to predict secondary VGO viscosity at $80{ }^{\circ} \mathrm{C}$.

\begin{tabular}{rcccccccc}
\hline & Abbott & Twu & Al-Mulla & $\begin{array}{c}\text { Aboul- } \\
\text { Seoud }\end{array}$ & $\begin{array}{c}\text { Sánchez- } \\
\text { Minero }\end{array}$ & Fang & Kotzakoulakis \\
\hline 1 & MIN E & -1368.7 & -260.5 & $-1.41 \times 10^{12}$ & -65.5 & NA & NA & $-22,586.0$ \\
2 & MAX E & 51.3 & 61.8 & 100.0 & 48.9 & NA & NA & 76.9 \\
3 & SE & 62.9 & 16.0 & $3.42 \times 10^{10}$ & 6.3 & NA & NA & $15,064.7$ \\
4 & RSE & 190.4 & 110.5 & $1.04 \times 10^{11}$ & 19.1 & NA & NA & $45,608.1$ \\
5 & SSE & 226.0 & 40.7 & $1.98 \times 10^{20}$ & 1.9 & NA & NA & $51,789.1$ \\
6 & LNR & -7.8 & -13.8 & $-1.60 \times 10^{11}$ & -13.9 & NA & NA & $-70,656.8$ \\
7 & HPR & 291.5 & 60.0 & 97.1 & 14.0 & NA & NA & 24.3 \\
8 & \#R- & 5 & 23 & 23 & 12 & NA & NA & 12 \\
9 & \#R+ & 19 & 1 & 1 & 12 & NA & NA & 12 \\
10 & Range R & 299.3 & 73.8 & $1.60 \times 10^{11}$ & 28.0 & NA & NA & $70,681.1$ \\
11 & \%AAD & 79.3 & 109.7 & $5.87 \times 10^{10}$ & 21.7 & NA & NA & 1259.9 \\
\hline
\end{tabular}

\subsection{Development of New Empirical Model}

The data in Table 5 indicated that the empirical model of Aboul-Seoud and Moharam [15] best predicted the viscosity of the secondary VGOs from Table 1. In their model, however, both VGO average boiling point and specific gravity have the same power of 0.2. Kotzakoulakis and George [21] proposed an empirical model where petroleum boiling point, and specific gravity have different values of the power term. Following the suggestion to separate the power term for VGO average boiling point and the specific gravity we explored the empirical model in the form:

$$
V i s=e^{e^{a A B P^{b} \cdot D 15^{c}}-d}+f
$$

where,

Vis = kinematic viscosity at $80^{\circ} \mathrm{C}, \mathrm{mm}^{2} / \mathrm{s}$;

$A B P=$ VGO average boiling point, $\mathrm{K}$;

$D 15=$ VGO density at $15^{\circ} \mathrm{C}, \mathrm{g} / \mathrm{cm}^{3}$;

$a, b, c, d, f=$ regression coefficients.

Employing the data from Table 1 along with computer algebra system Maple (and Global Optimization Toolbox) the following values for the regression coefficients were found:

- $\quad a=0.8611313197$

- $b=0.3967069960$;

- $c=0.2858346574$;

- $d=10.5837141796$;

- $f=3.669559682208$.

Figure 2 presents graphs of comparisons of measured against predicted by the empirical model developed in this work (Equation (14)) secondary VGO viscosity (Figure 2a) and that of Aboul-Seoud and Moharam [15] empirical model (Figure 2b). The data in Figure 2 show that the new empirical model distinguishes with a lower average absolute deviation (\%AAD). 


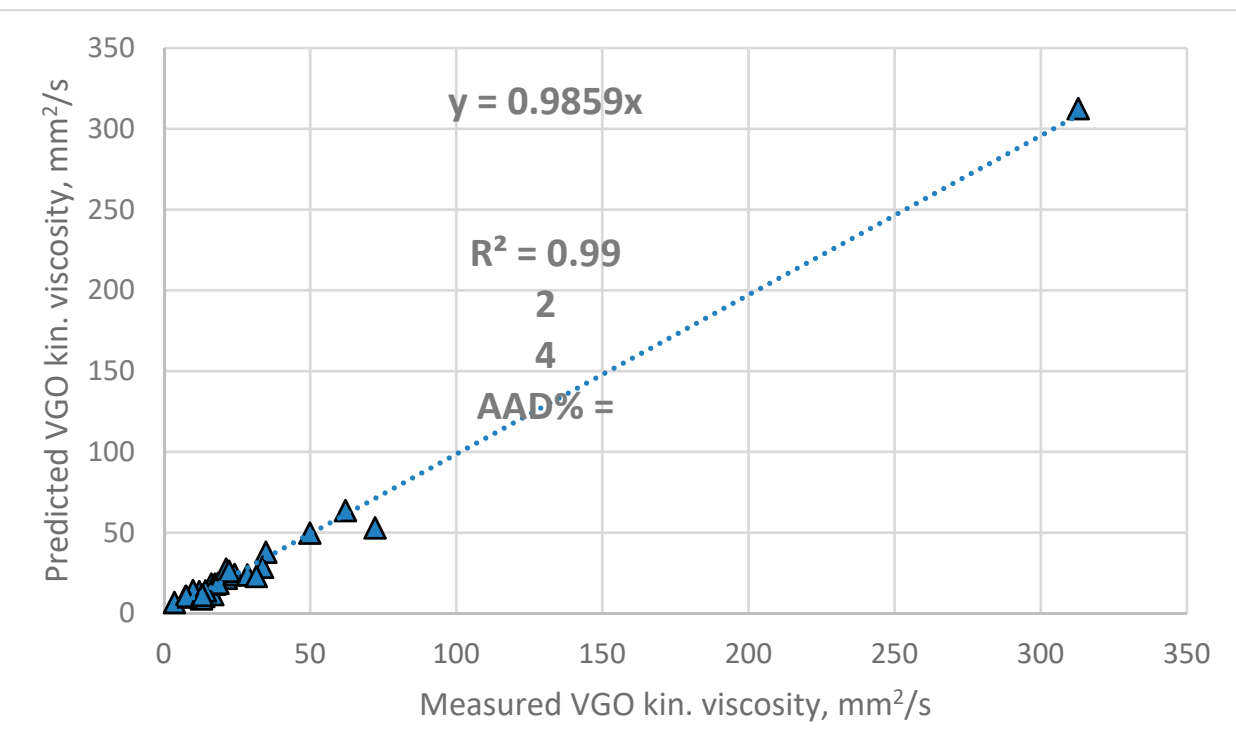

(a)

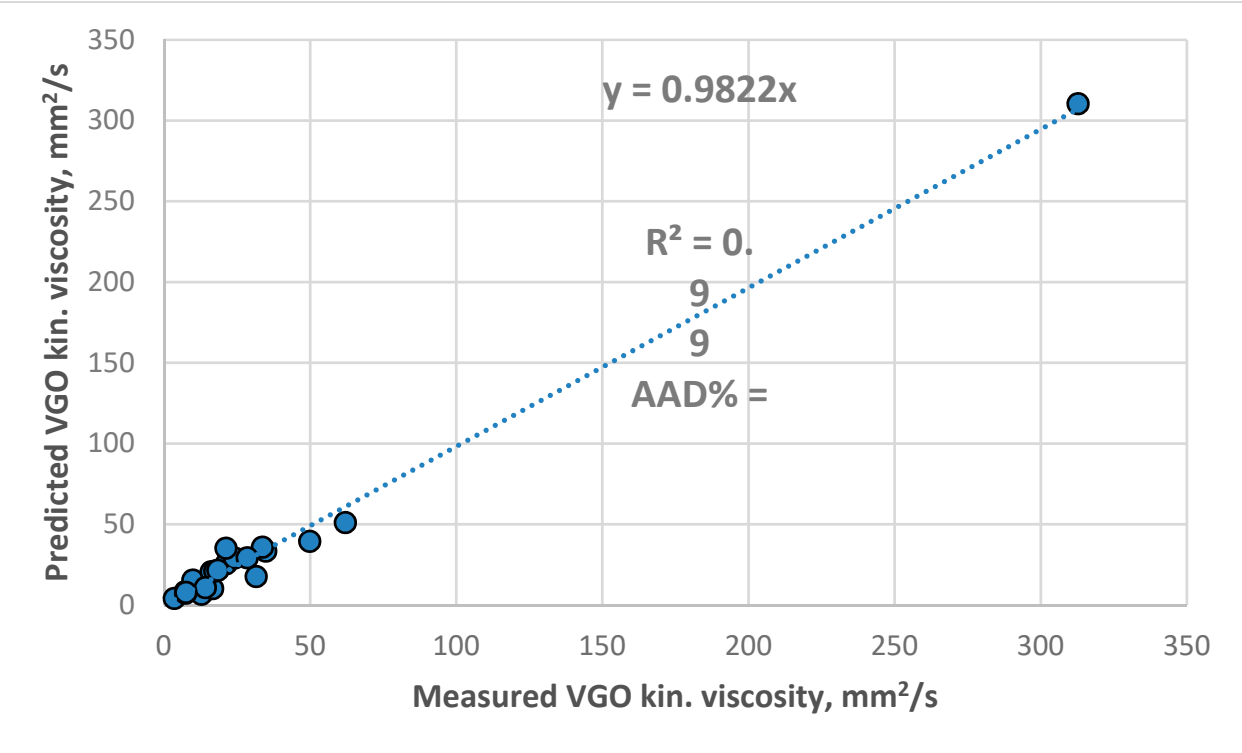

(b)

Figure 2. Comparison of measured against predicted by the empirical model developed in this work secondary VGO viscosity (a) and that of Aboul-Seoud and Moharam empirical model (b).

\subsection{Validation of the New Empirical Model}

Ten VGOs not included in the initial VGO database from Table 1 were examined for their viscosity at different temperatures. Table 6 presents data of specific gravity, average boiling point, measured kinematic viscosity at $80^{\circ} \mathrm{C}$ and predicted by Equation (15) and by the model of Aboul-Seoud and Moharam [15] for the 10 VGOs. It is evident from these data that Equation (14) predicts viscosity with 2.64 times as low \% AAD as that of the model of Aboul-Seoud and Moharam [15]. The new empirical model predicts viscosity of VGOs at $80^{\circ} \mathrm{C}$. In order to predict the secondary VGO viscosity at any temperature a relation of viscosity at $80{ }^{\circ} \mathrm{C}$ to that at any temperature is required. Aboul-Seoud and Moharam [15] developed an empirical model to predict viscosity at different temperatures from one test performed at any temperature. It has the form:

$$
\operatorname{Ln} \operatorname{Ln}(V I S+0.8)=\operatorname{Ln} \operatorname{Ln}\left(V I S_{0}+0.8\right)+a_{2} \operatorname{Ln}\left(\frac{T}{T_{O}}\right)
$$


where $V I S_{\mathrm{o}}$ is the single viscosity measurement $\left(\mathrm{mm}^{2} / \mathrm{s}\right)$ at temperature $T_{0}(\mathrm{~K})$ and $\mathrm{a}_{2}=-3.7$.

Table 6. Ten VGOs employed to compare the viscosity prediction ability of the empirical model developed in this work with the empirical model of Aboul-Seoud and Moharam [15] that showed the best prediction of the tested published models.

\begin{tabular}{|c|c|c|c|c|c|c|c|c|c|}
\hline $\mathrm{Nr}$ & Sample & SG & $\underset{{ }^{\circ} \mathrm{C}}{\mathbf{A B P}}$ & ARI & $\begin{array}{l}\text { Kin. vis. } \\
\text { at } 80^{\circ} \mathrm{C} \text {, } \\
\mathrm{mm}^{2} / \mathrm{s}\end{array}$ & $\begin{array}{c}\text { Predicted Viscosity } \\
\text { at } 80^{\circ} \mathrm{C} \text { by } \\
\text { Aboud-Seoul and } \\
\text { Moharam [15] } \\
\text { Empirical Model }\end{array}$ & $\begin{array}{l}\text { Predicted Viscosity } \\
\text { at } 80{ }^{\circ} \mathrm{C} \text { by the } \\
\text { Empirical Model } \\
\text { Developed in This } \\
\text { Work }\end{array}$ & $\begin{array}{l}\text { AAD\% } \\
\text { (Aboul- } \\
\text { Seoud and } \\
\text { Moharam } \\
\text { [15]) }\end{array}$ & $\begin{array}{l}\text { AAD\% } \\
\text { (This } \\
\text { Work) }\end{array}$ \\
\hline 1 & HAGO-5 & 0.971 & 397 & 2.4 & 13 & 10.1 & 11.5 & 22.1 & 11.5 \\
\hline 2 & LVGO-5 & 0.986 & 393 & 2.6 & 13 & 9.4 & 11.2 & 28.6 & 15.2 \\
\hline 3 & HVGO-5 & 1.015 & 476 & 3.4 & 57.5 & 45.5 & 53 & 20.8 & 7.8 \\
\hline 4 & $\begin{array}{c}\text { FCC } \\
\text { SLO-12 }\end{array}$ & 1.097 & 402 & 3.9 & 22.2 & 33 & 26.2 & 48.5 & 17.7 \\
\hline 5 & VBGO-1 & 0.940 & 439 & 2.1 & 14.7 & 12.0 & 14.6 & 18.2 & 0.4 \\
\hline 6 & VBGO-2 & 0.945 & 431 & 2.1 & 13.5 & 11.3 & 13.7 & 16.2 & 1.3 \\
\hline 7 & $\begin{array}{c}\text { FCC } \\
\text { SLO-13 }\end{array}$ & 1.053 & 366 & 3.2 & 14.5 & 12.6 & 12.0 & 13.4 & 17.2 \\
\hline 8 & $\begin{array}{c}\text { FCC } \\
\text { SLO-14 }\end{array}$ & 1.077 & 390 & 3.6 & 16.2 & 22.3 & 18.6 & 37.5 & 15.0 \\
\hline 9 & HTVGO-1 & 0.894 & 434 & 1.2 & 10.4 & 7.6 & 10.8 & 27.4 & 3.9 \\
\hline \multirow[t]{2}{*}{10} & HTVGO-2 & 0.890 & 431 & 1.2 & 9.6 & 7.1 & 10.4 & 25.9 & 8.2 \\
\hline & & & & & & & $\mathrm{AAD} \%$ & 25.9 & 9.8 \\
\hline
\end{tabular}

Kotzakoulakis and George [21] confirmed in their study, that $a_{2}$ is almost equal to -3.7 , with a small adjustment to be equal to -3.682 .

In order to verify the validity of $\mathrm{a}_{2}=-3.7$ the viscosity of the 10 VGOs was measured in the temperature range $40-100{ }^{\circ} \mathrm{C}$ (Table 7). By the use of Equation (15) and the data in Table $7 \mathrm{a}_{2}$ was calculated and it was found that $\mathrm{a}_{2}$ is not equal to -3.7 for the 10 studied VGOs. Figure 3 indicates that $\mathrm{a}_{2}$ varies between -2.57 and -4.17 for the 10 additionally studied VGOs. It also shows that for the VGOs having ARI equal or higher than $2.4 \mathrm{a}_{2}$ correlates with the VGO SG. The VGOs having ARI equal or below $2.1 \mathrm{a}_{2}$ is close to -3.7 and could be assumed to be -3.7 . For the VGOs having ARI equal or higher than $2.4 \mathrm{a}$ regression was developed to predict $\mathrm{a}_{2}$ from data about SG and ABP. It has the form:

$$
a_{2}=-12.0305+13.48785 * \mathrm{SG}+0.003598 * \mathrm{ABP} \mathrm{R}^{2}=0.99 \% \mathrm{AAD}=2.1
$$

Equation (17) suggests that increasing both $\mathrm{ABP}$ and SG leads to augmentation of $\mathrm{a}_{2}$. In other words, the heavier and higher boiling secondary VGOs will exhibit a steeper decrease in viscosity with enhancement of temperature. More data are needed to understand the relation of viscosity to temperature for VGOs having ARI lower than 2.

Table 7. Kinematic viscosity of the ten VGOs from Table 4 measured at different temperatures.

\begin{tabular}{|c|c|c|c|c|c|c|c|c|c|c|}
\hline \multirow[b]{2}{*}{$\mathbf{T}^{\circ} \mathrm{C}$} & \multicolumn{10}{|c|}{ Kinematic Viscosity, $\mathrm{mm}^{2} / \mathrm{s}$} \\
\hline & HAGO-5 & LVGO-5 & HVGO-5 & $\begin{array}{c}\text { FCC } \\
\text { SLO-12 }\end{array}$ & VBGO-1 & VBGO-2 & $\begin{array}{c}\text { FCC } \\
\text { SLO-13 }\end{array}$ & $\begin{array}{c}\text { FCC } \\
\text { SLO-14 }\end{array}$ & HTVGO-1 & HTVGO-2 \\
\hline 40 & & & & & & & 107.8 & 194.0 & & \\
\hline 50 & 29.6 & 30.8 & & 109.3 & 46.1 & 39.5 & 46.3 & 85.1 & 28.8 & 25.6 \\
\hline 60 & 18.7 & 18.5 & 118.6 & 53.7 & & & 29.8 & 44.8 & 19.6 & 17.7 \\
\hline 70 & 15.0 & 14.8 & 95.6 & 31.5 & & & 20.0 & 25.6 & 14.1 & 13.5 \\
\hline 80 & 13.0 & 13.0 & 57.5 & 22.2 & 14.7 & 13.5 & 14.5 & 16.2 & 10.4 & 9.6 \\
\hline 90 & 11.3 & 11.7 & 46.3 & 17.3 & 8.5 & 8.2 & & & & \\
\hline 100 & & & 24.4 & & & & & & & \\
\hline
\end{tabular}




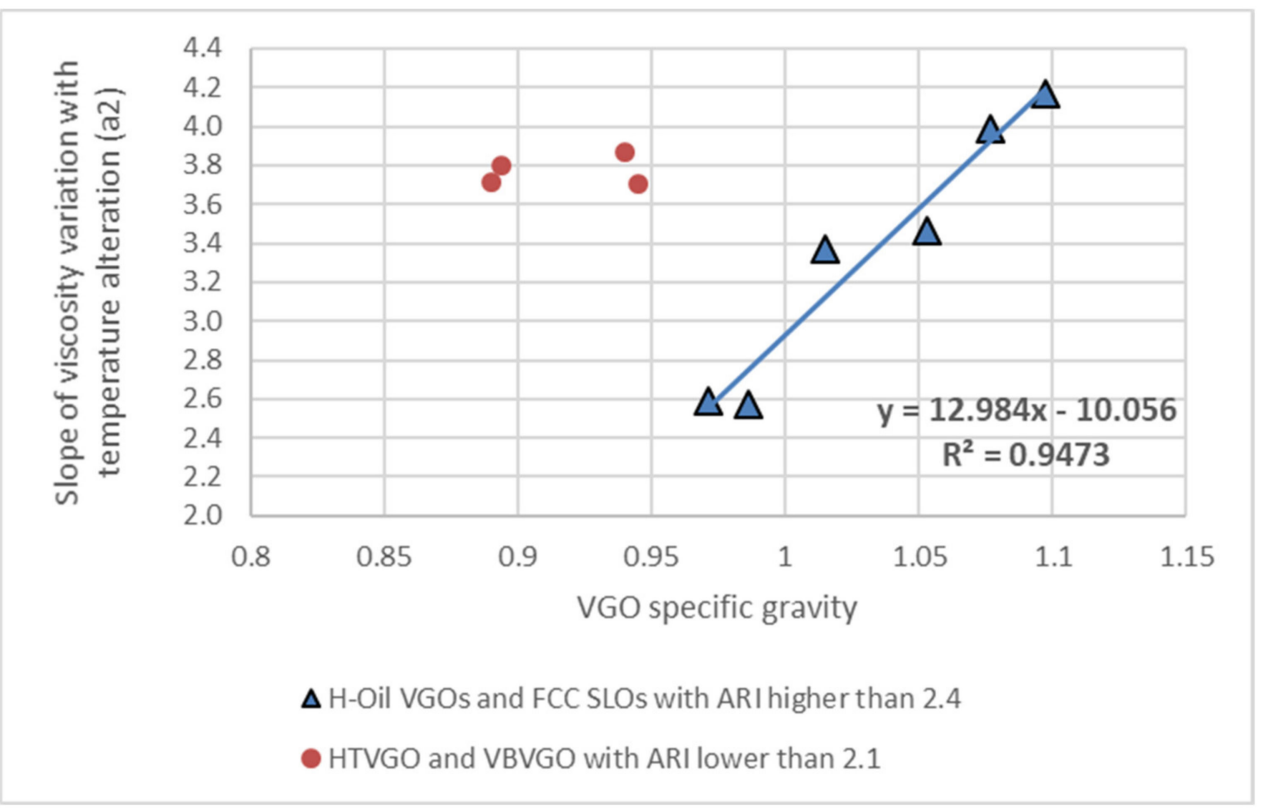

Figure 3. Relation of $\mathrm{a}_{2}$ to specific gravity of the 10 VGOs from Table 4 .

Another issue with the prediction of VGO viscosity at different temperatures is the accuracy of the measurement of viscosity at lower temperatures. For example, the viscosity of HVGO- 5 at $50{ }^{\circ} \mathrm{C}$ was not possible to measure due to its lower fluidity. Table 8 presents data of kinematic viscosity measured six times at 60,80 , and $100{ }^{\circ} \mathrm{C}$ for the secondary VGOs-HVGO-5 and LVGO-5. These data indicate the error of measurement linearly increases with decreasing of the temperature of measurement (Figure 4). It becomes clear from these data that prediction of viscosity of VGOs at lower temperature will suffer from a lower accuracy.

The newly developed empirical model (Equation (14)) along with Equations (15) and (16) were used to estimate viscosity of the 10 VGOs at the temperature range $40-100{ }^{\circ} \mathrm{C}$ and were compared with the empirical model of Aboul-Seoud and Moharam [15] for 42 experimental points. Table S1 (Supplementary Materials) presents data for the measured and estimated by the model developed in this work and that of Aboul-Seoud and Moharam [15] along with data for average deviation, \% AAD, and standard error. These data show that the newly developed empirical model is superior with lower values for the average deviation $\left(7.4 \mathrm{~mm}^{2} / \mathrm{s}\right.$ for this work versus $9.4 \mathrm{~mm}^{2} / \mathrm{s}$ of Aboul-Seoud and Moharam), \% AAD (13.8\% versus 24.9\% for Aboul-Seoud and Moharam), and standard error (18.5 versus 28.5 for Aboul-Seoud and Moharam).

Table 8. Kinematic viscosity measured six times at 60,80 , and $100{ }^{\circ} \mathrm{C}$ for the secondary VGOsHVGO-5 and LVGO-5.

\begin{tabular}{cccc}
\hline & HVGO-5 & & LVGO-5 \\
\hline Temperature ${ }^{\circ} \mathrm{C}$ & 80 & 100 & 60 \\
1st measurement & 72.6 & 25.7 & 46.7 \\
2nd measurement & 59.3 & 24.1 & 27.8 \\
3rd measurement & 57.4 & 24.1 & 25.9 \\
4th measurement & 51.9 & 24.1 & 25.9 \\
5th measurement & 51.9 & 24.1 & 27.8 \\
6th measurement & 51.9 & 24.5 & 30.8 \\
Average & 57.5 & 24.4 & 79.4 \\
$\sigma^{2}$ & 65.4 & 0.4 & 8.9 \\
$\sigma$ & 8.1 & 0.7 & 57.8 \\
\hline
\end{tabular}




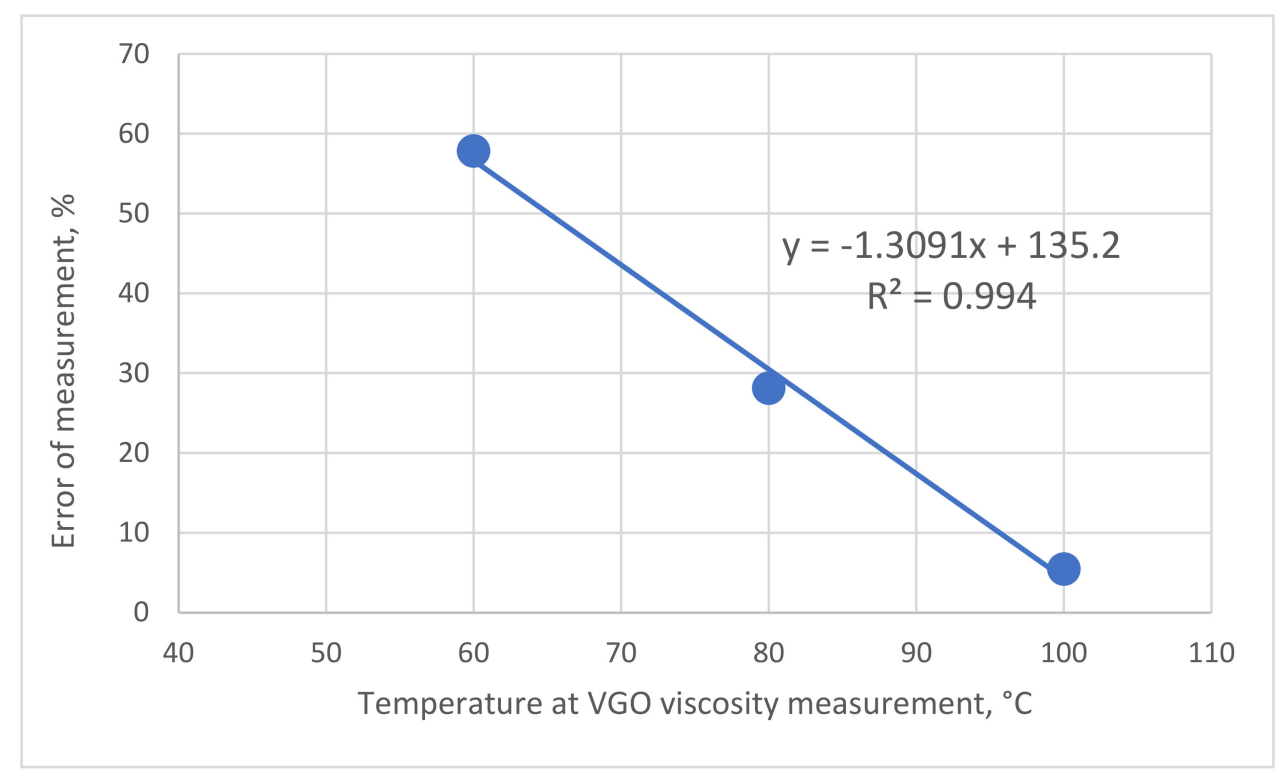

Figure 4. Dependence of error of measurement of VGO viscosity on the temperature of the measurement.

\section{Conclusions}

This work presented characterization data and viscosity of 34 secondary VGOs with aromatics content reaching up to $100 \mathrm{wt} . \%$. The secondary VGO viscosity goes up with the enhancement of average boiling point and specific gravity. The viscosity of the secondary vacuum gas oils is best predicted by the use of data for average boiling point and specific gravity (density). The empirical model of Aboul-Seoud and Moharam [15] among the seven tested empirical models was found to predict the secondary VGO viscosity with the highest accuracy. A modification of Aboul-Seoud and Moharam model by separating the power terms accounting for the distinct effects of specific gravity and average boiling point improves the accuracy of viscosity prediction. It was found out that the relation of slope of viscosity decrease with temperature enhancement for the secondary VGO is not a constant. It was discovered that this slope increases with ABP and SG augmentation, a fact that has not been discussed before. Moreover, the VGOs having different aromatic ring indexes seem to obey a different dependence of the slope of viscosity decrease with temperature enhancement. The accuracy of prediction of oil viscosity depends on the temperature of viscosity measurement. The lower the viscosity measurement temperature the higher the error of measurement can be depending on the low temperature properties of the studied oils. In this work, it was found that the error of VGO viscosity measurement linearly increases with decreasing the temperature of the measurement. Therefore, models predicting secondary VGO viscosities at temperatures lower than $80^{\circ} \mathrm{C}$ can suffer from a lower accuracy.

Supplementary Materials: The following are available online at https: / www.mdpi.com/article / 10.3390/resources10080082/s1, Table S1: 42 data points for measured at different temperatures VGO viscosities and predicted by the empirical model developed in this work and by the model of Aboul-Seoud and Moharam [15].

Author Contributions: Conceptualization, E.S.; Data curation, S.N. and R.K.D.; Formal analysis, D.Y.; Investigation, K.Z. and L.T.-Y.; Methodology, S.S.; Software, V.A. and D.D.S.; Supervision, K.A.; Writing-original draft, D.S.S. and I.K.S. All authors have read and agreed to the published version of the manuscript.

Funding: This research was funded by Asen Zlatarov University-Burgas, Project: Information and Communication Technologies for a Digital Single Market in Science, Education and Security DCM \# 577/17 August 2018 (2018-2021). 
Institutional Review Board Statement: Not applicable.

Informed Consent Statement: Not applicable.

Data Availability Statement: Not applicable.

Acknowledgments: The authors are grateful for the support provided by the Bulgarian Ministry of Education and Science under the National Research Programme "Information and Communication Technologies for a Digital Single Market in Science, Education and Security" approved by DCM \# 577/17 August 2018.

Conflicts of Interest: The authors declare no conflict of interest.

\section{Nomenclature}

$\begin{array}{llll}A B P & \text { Average boiling point } & K & n_{D 20}=\text { refractive index at } 20^{\circ} \mathrm{C} \\ S G & \text { Specific gravity } & E & \text { Error } \\ V I S & \text { Kinematic viscosity, cSt } & \mu & \text { Dynamic viscosity, } \mathrm{cP} \\ A P I & \text { API gravity } & S E & \text { Standard error } \\ A R I & \text { Aromatic ring index } & R S E & \text { Relative standard error } \\ d_{15} & \text { Density at } 15^{\circ} \mathrm{C}, \mathrm{g} / \mathrm{cm}^{3} & S S E & \text { Sum of squared errors } \\ M W & \text { Molecular weight, } & R & \text { Residual } \\ V G O & \text { Vacuum gas oil } & \mathrm{K} w & \text { Watson K factor } \\ \% A A D & \text { Average absolute deviation, } \% & M I N E & \text { Minimum error } \\ M A X E & \text { Maximum error } & L N R & \text { Lowest number residual } \\ H N R & \text { Highest number residual } & \# R- & \text { Number of negative residuals } \\ \# R+ & \text { Number of positive residuals } & \mathrm{ICrA} & \text { Inter-criteria analysis }\end{array}$

$\sigma$

Standard deviation of viscosity measure-

ment

\section{References}

1. Touloukian, Y.S.; Saxena, S.C.; Hestermaus, P. Thermophysical Properties of Matter-TPRC Data Series, II. Viscosity; Purdue Research Foundation: West Lafayette, IN, USA, 1975.

2. $\quad$ Reid, R.C.; Prausnitz, J.M.; Sherwood, T.K. The Properties of Gases and Liquids, 3rd ed; McGraw-Hill: New York, NY, USA, 1977. Available online: https:/ / www.worldcat.org/title/properties-of-gases-and-liquids/oclc/560350942? referer=di\&ht=edition (accessed on 28 June 2021).

3. Stephan, K.; Lucas, K.D. Viscosity of Dense Fluids; Plenum Press: New York, NY, USA, 1979.

4. Abbott, M.M.; Kaufmann, T.G.; Domash, L.A. Correlation for predicting liquid viscosities of petroleum fractions. Can. J. Chem. Eng. 1971, 49, 379-384. [CrossRef]

5. Twu, C.H. Internally consistent correlation for predicting liquid viscosities of petroleum fractions. Ind. Eng. Chem. Proc. Des. Dev. 1985, 24, 1293-1297. [CrossRef]

6. $\quad$ Reid, R.C.; Prausnitz, J.M.; Poling, B.E. The Properties of Gases and Liquids, 4th ed; McGraw-Hill: New York, NY, USA, 1987. Available online: https:/ / www.worldcat.org/title/properties-of-gases-and-liquids/oclc/14520133 (accessed on 28 June 2021).

7. Viswanath, D.S.; Natarajan, G. Data Book on the Viscosity of Liquids; Hemisphere Publishing: New York, NY, USA, 1989.

8. Miadonye, A.; Puttagunta, V.R.; Singh, B. Prediction of the viscosity of crude oil fractions from a single measurement. Chem. Eng. Commun. 1993, 122, 195-199. [CrossRef]

9. Monnery, W.D.; Svrcek, W.Y.; Mehrotra, A.K. Viscosity: A critical review of practical predictive and correlative methods. Can. J. Chem. Eng. 1995, 73, 3-40. [CrossRef]

10. Mehrotra, A.K. A simple equation for predicting the viscosity of crude-oil fractions. Chem. Eng. Res. Des. 1995, 73, 87-90.

11. Moharam, H.M.; Al-Mehaideb, R.A.; Fahim, M.A. New correlation for predicting the viscosity of heavy petroleum fractions. Fuel 1995, 74, 1776-1779. [CrossRef]

12. Mehrotra, A.K.; Monnery, W.D.; Svrcek, W.Y. A review of practical calculation methods for the viscosity of liquid hydrocarbons and their mixtures. Fluid Phase Equilibria 1996, 117, 344-355. [CrossRef]

13. Wakabayashi, T. Viscosity correlation with specific gravity and molecular weight of crude oil fractions. Fuel 1997, 76, 1049-1056. [CrossRef]

14. Fang, W.; Lei, Q. Generalized correlation for predicting the kinematic viscosity of liquid petroleum fractions. Fluid Phase Equilibria 1999, 166, 125-139. [CrossRef]

15. Aboul-Seoud, A.L.; Moharam, H.M. A generalized viscosity correlation for undefined petroleum fractions. Chem. Eng. J. 1999, 72, 253-256. [CrossRef] 
16. Al-Maamari, R.S.; Houache, O.; Abdul-Wahab, S.A. New correlating parameter for the viscosity of heavy crude oils. Energy Fuels 2006, 20, 2586-2592.

17. Sánchez-Minero, F.; Sánchez-Reyna, G.; Ancheyta, J.; Marroquin, G. Comparison of correlations based on API gravity for predicting viscosity of crude oils. Fuel 2014, 138, 193-199.

18. Bahadori, A. Prediction of heavy-oil viscosities with a simple correlation approach. Oil Gas Facil. 2015, 2, 66-72.

19. Marinov, I.; Stratiev, D.; Sharafutdinov, I.; Rudnev, N.; Petkov, P. Evaluation of available empirical correlations for viscosity prediction of petroleum fractions originating from different crudes. Oil Gas Eur. Mag. 2016, 42, 145-150.

20. AlMulla, H.A.; Albahri, T.A. Estimating the kinematic viscosity of petroleum fractions. Int. J. Thermophys. 2017, $38,58$.

21. Kotzakoulakis, K.; George, S.C. A simple and flexible correlation for predicting the viscosity of crude oils. J. Pet. Sci. Eng. 2017, $158,416-423$.

22. Kamel, A.; Alomair, O.; Elsharkawy, A. Measurements and predictions of Middle Eastern heavy crude oil viscosity using compositional data. J. Pet. Sci. Eng. 2019, 173, 990-1004.

23. Kumar, R.; Maheshwari, S.; Voolapalli, R.K.; Upadhyayul, S. Investigation of physical parameters of crude oils and their impact on kinematic viscosity of vacuum residue and heavy product blends for crude oil selection. J. Taiwan Inst. Chem. Eng. 2021, 120, 33-42.

24. Gabitto, J. Experimental and Theoretical Determination of Heavy Oil Viscosity under Reservoir Conditions. 2003. Available online: https: / / digital.library.unt.edu/ark:/67531/metadc736112/ (accessed on 28 June 2021).

25. Khemka, Y.; Abutaqiya, M.I.L.; Sisco, C.J.; Chapman, W.G.; Vargas, F.M. Accurate prediction of the viscosity of light crude oils using one-parameter friction theory: Effect of crude oil characterization methods and property correlations. Fuel 2021, 283, 118926.

26. Loria, H.; Motahhari, H.; Satyro, M.A.; Yarranton, H.W. Process simulation using the expanded fluid model for viscosity calculations. Chem. Eng. Res. Des. 2014, 92, 3083-3095.

27. Hadavimoghaddam, F.; Ostadhassan, M.; Heidaryan, E.; Sadri, M.A.; Chapanova, I.; Popov, E.; Cheremisin, A.; Rafieepour, S. Prediction of dead oil viscosity: Machine learning vs. classical correlations. Energies 2021, 14, 930. [CrossRef]

28. Torabi, F.; Abedini, A.; Abedini, R. The development of an artificial neural network model for prediction of crude oil viscosities. Pet. Sci. Technol. 2011, 29, 804-816. [CrossRef]

29. Hemmati-Sarapardeh, A.; Aminshahidy, B.; Pajouhandeh, A.; Yousefi, S.H.; Hosseini-Kaldozakh, S.A. A soft computing approach for the determination of crude oil viscosity: Light and intermediate crude oil systems. J. Taiwan Inst. Chem. Eng. 2016, 59, 1-10. [CrossRef]

30. Ghorbani, B.; Hamedi, M.; Shirmohammadi, R. A novel multi-hybrid model for estimating optimal viscosity correlations of Iranian crude oil. J. Pet. Sci. Eng. 2016, 142, 68-76. [CrossRef]

31. Oloso, M.A.; Hassan, M.G.; Bader-El-Den, M.B.; Buick, J.M. Ensemble SVM for characterisation of crude oil viscosity. J. Pet. Explor. Prod. Technol. 2017, 8, 531-546. [CrossRef]

32. Oloso, M.A.; Khoukhi, A.; Abdulraheem, A.; Elshafei, M. Prediction of crude oil viscosity and gas/oil ratio curves using recent advances to neural networks. In Proceedings of the SPE/EAGE Reservoir Characterization \& Simulation Conference, Abu Dhabi, United Arab Emirates, 19-21 October 2009.

33. Wang, G.; Liu, Y.; Wang, X.; Xu, C.; Gao, J. Studies on the catalytic cracking performance of coker gas oil. Energy Fuels 2009, 23, 1942-1949. [CrossRef]

34. Stratiev, D.; Shishkova, I.; Yankov, V.; Yordanov, D.; Tankov, I. Fluid catalytic cracking of H-Oil derived heavy oils. Oxid Commun. 2020, 43, 289-301.

35. Sheng, Q.; Wang, G.; Liu, Y.; Husein, M.M.; Gao, C.; Shi, Q.; Gao, J. Combined hydrotreating and fluid catalytic cracking processing for the conversion of inferior coker gas oil: Effect on nitrogen compounds and condensed aromatics. Energy Fuels 2018, 32, 4979-4987. [CrossRef]

36. Stratiev, D.; Shishkova, I.; Ivanov, M.; Dinkov, R.; Georgiev, B.; Argirov, G.; Atanassova, V.; Vassilev, P.; Atanassov, K.; Yordanov, D.; et al. Catalytic cracking of diverse vacuum residue hydrocracking gas oils. Chem. Eng. Technol. 2021, 44, 997-1008. [CrossRef]

37. Mondal, S.; Yadav, A.; Kumar, R.; Bansal, V.; Das, S.K.; Christopher, J.; Kapur, G.S. Molecular-level structural insight into clarified oil by nuclear magnetic resonance (NMR) spectroscopy: Estimation of hydrocarbon types and average structural parameters. Energy Fuels 2017, 31, 7682-7692. [CrossRef]

38. Redelius, P.; Soenen, H. Relation between bitumen chemistry and performance. Fuel 2015, 140, 34-43. [CrossRef]

39. Diarov, I.N.; Batueva, I.U.; Sadikov, A.N.; Colodova, N.L. Chemistry of Crude Oil; Chimia Publishers: St. Peterburg, Russia, 1990. (In Russian)

40. Liñan, L.Z.; Lima, N.M.N.; Maciel, M.R.W.; Filho, M.; Medina, L.C.; Embiruçu, M. Correlation for predicting the molecular weight of Brazilian petroleum residues and cuts: An application for the simulation of a molecular distillation process. J. Pet. Sci. Eng. 2011, 78, 78-85. [CrossRef]

41. Stratiev, D.S.; Marinov, I.M.; Shishkova, I.K.; Dinkov, R.K.; Stratiev, D.D. Investigation on feasibility to predict the content of saturate plus mono-nuclear aromatic hydrocarbons in vacuum gas oils from bulk properties and empirical correlations. Fuel 2014, 129, 156-162. [CrossRef]

42. Abutaqiya, M. Advances in Thermodynamic Modeling of Nonpolar Hydrocarbons and Asphaltene Precipitation in Crude Oils. Ph.D. Thesis, Rice University, Houston, TX, USA, 2019. 
43. Abutaqiya, M.I.L.; AlHammadi, A.A.; Sisco, C.J.; Vargas, F.M. Aromatic ring index (ARI): A Characterization factor for nonpolar hydrocarbons from molecular weight and refractive index. Energy Fuels 2021, 35, 1113-1119. [CrossRef]

44. Atanassov, K. Intuitionistic fuzzy sets. In VII ITKR's Session; Central Institute for Scientific and Technical Information: Sofia, Bulgaria, 1983. (In Bulgarian)

45. Atanassov, K. Intuitionistic fuzzy sets. Fuzzy Sets Syst. 1986, 20, 87-96. [CrossRef]

46. Atanassov, K. Intuitionistic Fuzzy Sets: Theory and Applications; Springer Physica: Berlin/Heidelberg, Germany, 1999.

47. Atanassov, K. On Intuitionistic Fuzzy Sets Theory; Springer: Berlin/Heidelberg, Germany, 2012.

48. Atanassov, K. Generalized index matrices. Comptes Rendus l'Acad. Bulg. Sci. 1987, 11, 15-18.

49. Atanassov, K. Index Matrices: Towards an Augmented Matrix Calculus; Springer: Cham, Switzerland, 2014.

50. InterCriteria Research Portal. 2015. Available online: http:/ / www.intercriteria.net/publications (accessed on 28 June 2021).

51. Stratiev, D.S.; Shishkova, I.K.; Dinkov, R.K.; Petrov, I.P.; Kolev, I.V.; Yordanov, D.; Sotirov, S.; Sotirova, E.; Atanassova, V.; Ribagin, S.; et al. Empirical models to characterize the structural and physio-chemical properties of vacuum gas oils with different saturate contents. Resources 2021, 10, 71. [CrossRef]

52. Hernández, E.A.; Sánchez-Reyna, G.; Ancheyta, J. Comparison of mixing rules based on binary interaction parameters for calculating viscosity of crude oil blends. Fuel 2019, 249, 198-205. [CrossRef] 